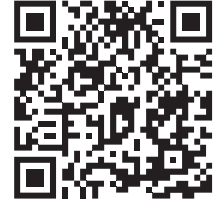

* Comisión de Bioética del Estado de Campeche. Médico Cirujano con Especialidad en Patología Clínica, México.

Correspondencia: ECS, eduardogarsol@gmail.com Conflicto de intereses: Ninguno.

Citar como: García SE. Poder del médico. Rev CONAMED. 2021; 26(4): 202-203. https://dx.doi. org/10.35366/102508

Financiamiento: Ninguno.

\title{
Poder del médico
}

\section{Power of the physician}

\author{
Eduardo García Solís*
}

Palabras clave: Médico, poder, paciente. Keywords: Physician, power, patient.

\section{Estimado Editor}

Desde los tiempos de Hipócrates, hace más de 2,000 años, se ha considerado que el médico tiene un poder, el poder de la curación. No obstante, en el devenir de los años, ese poder en ocasiones se ha degradado. Como se reportó en enero de 2016, un médico de renombre agredió sexualmente a una paciente de raza negra, en uno de los hospitales académicos más prestigiosos de los EUA. Sucedió justo en la sala de emergencias, un lugar al que acudió con la esperanza de recibir atención, e inicialmente nadie le creyó. Cuando el análisis de semen mostró que, de hecho, tenía razón, que este médico la había drogado y procedió a eyacular sobre ella, muchos cuestionaron cómo podría haber sido posible. Para la mayoría del personal de salud, esto parecería sorprendente y difícil de creer. Probablemente su poder, prestigio y sentido de invencibilidad fueron todos factores que realmente lo hicieron sentir que podría salirse con la suya, cuántos casos similares se conocen. Existen médicos que se consideran non plus ultra, se reportan casos de abuso sexual, físico, psicológico² y la mayoría de las veces no pasa nada.

En los hospitales se han creado y perpetuado jerarquías obsoletas, que han dado origen al poder en medicina, situación que ha llevado al abuso no sólo de pacientes, sino también de estudiantes de medicina y otros profesionales de la salud. En la enseñanza de la medicina en las residencias médicas existen médicos que consideran tener el poder de influir sobre sus subalternos, no sólo en lo académico, en ocasiones en su vida privada, aunado a la falta de supervisión de autoridades sanitarias y educativas. Si los médicos tienen el potencial de volverse abusivos, ¿por qué lo hacen y cómo podríamos detenerlo? Algunos han señalado la creciente epidemia de agotamiento entre los médicos en formación como contribuyentes. En un estudio, ${ }^{3}$ los investigadores descubrieron que los estudiantes de medicina que estaban más «agotados» tenían más probabilidades de comportarse de manera no profesional y con menor humanismo en el cuidado de los pacientes, especialmente los vulnerables. En esa población en especial el paciente cree que el médico tiene un poder apostólico, todo lo que éste dijera sería aceptado y creído como verdad. La responsabilidad del médico es con sus pacientes, estudia medicina para ayudar. Algunos consideran que tienen un poder, en ocasiones, entre decidir la vida o la muerte, como sucede con la eutanasia, sin olvidar el poder económico, en donde los médicos hacen de la profesión un lucro. 
Otra razón puede ser que no estamos seleccionando el tipo correcto de personas para ser médicos. En México, los sistemas de admisión médica están orientados a los puntajes de los exámenes, lo que significa que un estudiante con buenas calificaciones es excelente para estudiar medicina. Pero eso no necesariamente se traduce en lo que los pacientes suelen considerar importante: un médico que los escucha, se preocupa, tiene empatía y los trata como un ser humano que solicita ayuda. La investigación ha demostrado que la inteligencia emocional (emotional quotient, EQ por sus siglas en inglés) puede ser de utilidad, en contraste con el cociente intelectual (intelligence quotient, IQ por sus siglas en inglés). Algunas escuelas de medicina están cambiando para cambiar sus criterios de admisión y reflejar mejor esta necesidad, pero la mayoría no.

Pero además de estas razones, no debemos subestimar el hecho de que el poder corrompe inherentemente, en especial cuando no hay un sistema para mantenerlo bajo control. Muchos de los prestigiosos médicos que se salieron con la suya de dañar a otros han sido protegidos por sus instituciones.

En la Facultad de Medicina de Yale ${ }^{4}$ un médico siguió siendo director de su Instituto de investigación y fue invitado a regresar como jefe de su división después de acosar sexualmente a estudiantes. La realidad es que los médicos de renombre son importantes para las instituciones. Algunos aportan grandes cantidades de becas de investigación, otros aumentan la influencia y el prestigio del lugar donde trabajan, pero las personas que tienen el poder de hacer algo sobre el abuso deben preguntarse ¿la seguridad de un paciente no vale más que salvar el prestigio o proteger el dinero de la investigación?
El poder «infiltra toda nuestra sociedad y todos nuestros actos, querámoslo o no». ${ }^{5}$ La gran recomendación para irnos al lado positivo del poder es buscar la transparencia, claridad, información, defender los derechos de los pacientes y sus intereses.

Los pacientes merecen los mejores médicos, pero los mejores médicos no siempre son los más famosos. Cuando se trata de ayudar, al paciente no le importará cuántos títulos, publicaciones y premios están detrás del nombre de sus médicos; al presentarse una enfermedad, deseará a alguien que esté a su lado, tomándole de la mano, tratándole con respeto y cuidado, reconociendo que es un ser humano. Los médicos que piensan que son Dios no podrán hacer esto.

No necesitamos médicos más poderosos en medicina, lo que necesitamos son buenos médicos.

\section{AGRADECIMIENTOS}

A la Comisión de Bioética del Estado de Campeche.

\section{REFERENCIAS}

1. One Night at Mount Sinai, Aja Newman went to the emergency room for shoulder pain. Her doctor was a superstar. What is the worst that could happen? The Cut, Oct 15, 2019.

2. Fnais N, Soobiah C, Hong Chen M, Lillie E, Perrier L, Tashkhandi M et al. Acoso y discriminación en la formación médica: una revisión sistemática y metaanálisis. Acad Med. 2014; 89 (5): 817-827. doi: 10..1097

3. Igde FA, Sahin MK. Changes in empathy during medical education: an example from Turkey. Pak J Med Sci. 2017; 33 (5): 1177-1187.

4. Yale medical school removes doctor after sexual harassment finding, The New York Times, 14 November, 2014.

5. Baeza H. El poder del médico. Revista de la SEMC 2004; (60): 13-18. Disponible en: www.mgyfsgm-org/ medicinageneral/revista_60/pdf 